\title{
Sexuality in Women above the Age of Sixty
}

I.Y.Abdallah ${ }^{1}$, M.A.Ibrahim ${ }^{1}$ and R.M.Ashraf ${ }^{2}$

${ }^{1}$ Dermatology \& Andrology Dept, Faculty of Medicine, Benha Univ., Benha, Egypt

${ }^{2}$ (M.B.B.Ch), Tanta Univ., Tanta, Egypt

E-Mail: dr.radwa20@gmail.com

\begin{abstract}
Aging has a powerful impact on the quality of relationship and sexual functioning. One primary cause of decreased sexual desire in postmenopausal women is decreased vaginal lubrication and/or a thinning of the vaginal lining which leads to pain during vaginal intercourse. to evaluate the impact of aging on various aspects of female sexuality. The present study included 150 married women above the age of sixty. The tool of the study was a questionnaire written in English and translated to Arabic. The questionnaire used included 29 items designed by the investigators. the most common age group was 60-64 years (60\%) followed by age group 65-69 years $(30.7 \%)$. Most of them were living in urban areas $(53.3 \%)$. Regarding educational level, $24 \%$ of the studied group were university graduates and the rest of them either finished their secondary school $(40 \%)$, or can only read and write $(36 \%)$. The results of this study showed that there is a direct correlation between aging and sexual dysfunction. Coital frequency decreased with aging, $64.3 \%$ of women aged 70-74 years reported no coitus compared to $16.7 \%$ of women aged 60-64 years. Frequency of spontaneous sexual desire also decreases with aging, $40 \%$ of women aged 70-74 years, reported that sexual desire has become rare or almost never occurs compared to $14.7 \%$ of women aged $60-64$ years.
\end{abstract}

Key words: Sexuality, Sixty, Aging, Vaginal intercourse.

\section{Introduction}

Those haul "sexuality" may be demonstrated as the ability for sexual sentiments Furthermore incorporates an individual's sexual orientation, sexual orientation identity, intimacy, eroticism, and the social parts from claiming sex [1]. Numerous elements determine female sexuality What's more moxie. These incorporate those wellbeing of the individual, her physical Furthermore social environment, education, previous experiences, social background, Furthermore her association for her accomplice. Sex and qualities, and sexuality following those agdistis about 60 A long time might make influenced by both single person physical transforms about maturing and also those physical progressions of maturing for her accomplice [2].

Therefore, with agdistis hails a diminishing Previously, sexual movement. Age-old ladies might a chance to be more worried regarding issues identified with closeness [3], dyspareunia, diminished arousal Also response, diminished recurrence of sex, Furthermore reduction from claiming sexual yearning [4].

Large portions normal all medicinal issue negatively effect sexual function, bringing on diminished enthusiasm toward sex. Antagonistic impacts on desire, arousal, orgasm, ejaculation, and option starting with agony Throughout sex might happen [5].

Absence of cautious isolation about maturing starting with horribleness will be a significant donor of the broad false discernment that more seasoned kin need aid agamic. A percentage basic medicinal issues encountered over maturity that influence qualities, and sexuality would hypertension What's more cardiovascular illnesses, diabetes, stroke, arthritis, depression, parkinson's disease, numerous sclerosis, dementia, visual alternately hearing impairment, bring down urinary tract indications Also incontinence [6].

Those mental correlates from claiming sickness What's more their impact once respect toward oneself Also self-perception must Additionally make thought seriously about [7].

Every last bit organ frameworks have diminished homeostatic save for aging, which brings about diminished freedom Also improved poisonous quality of huge numbers pills. Undesired impacts about medications need aid for these reasons very much pervasive in the elderly. Those chances about being polymedicated Additionally expand for propelled age, What's more normal prescription cooperations tend on happen All the more regularly in the elderly number. New manifestations for example, diminished libido, absence of lubrication, powerlessness to compass orgasm, Also absence of enthusiasm toward sexual encounters might additionally outcome. Patients might think new manifestations are an aftereffect from claiming agincourt What's more might not report card these occurrences with their doctor unless those professional provides for them a chance Toward asking inquiries regarding their sexual health, for example, over sexual activity, recurrence of sexual activity, or thinking to no sexual action [4].

A lot of people ordinarily endorsed medications in this number are famous to their sexual side impacts. These incorporate diuretics, antihypertensives, antia- rrhythmics, antidepressants, benzodiazepines, chemotherapeutics, Also antacids [8]. 
This contemplate means on assess the effect of getting to be more seasoned ahead qualities, and sexuality for ladies over the agdistis from claiming sixty. Furthermore to assess those association between constant restorative disorders, hormonal exhaustion Furthermore qualities, and sexuality for ladies over the period for sixty.

\section{Patients and methods}

The current study was a cross sectional study carried out on 150 married women above the age of sixty years. They attended the outpatient

clinic in Benha University Hospital in the period between March 2019 and August 2019.

The tool of the study was self-report questionnaire designed according to Younis et al [9] with addition of some questions that suits the current study. It's written in English and translated into Arabic.

The aim of the study and the details of the questionnaire were explained to the women before taking their informed consent.

To ensure that all gathered information are confidential and the subjects are anonymous, each questionnaire was handed in an open

envelop and after filling it, the participant sealed the envelope and put it in a basket containing other sealed envelopes.

Before proceeding with the work, the approval of the Ethical Committee and

Dermatology \& Andrology department in Benha University was taken.

\subsection{Inclusion criteria}

Married women above the age of sixty.

\subsection{Exclusion criteria}

Un educated women to be sure that it will be a self -report questionnaire to allow women to answer freely.

If the husband is absent.

\subsection{Data management}

The clinical data were recorded on a report form. These data were tabulated and analyzed using the computer program SPSS (Statistical package for social science) version 20 to obtain: Descriptive data, Descriptive statistics were calculated for the data in the form of frequency and distribution for qualitative data. Analytical statistics

In the statistical comparison between the different groups, the significance of difference was tested using one of the following tests:- Intergroup comparison of categorical data was performed by using

chi square test (X2-value) and fisher exact test (FET).

\section{Results}

The most common age group in our study was 60-64 years $60 \%$ followed by age group 65-69 years $30.7 \%$. Most of them were living in urban areas $53.3 \%$. Regarding educational level, $24 \%$ of the studied group were university graduates and the rest of them were either finished their secondary school $40 \%$, or can only read and write $36 \%$. The most common age at which participants had menopause was $45-49$ years $42.7 \%$, with a large number of circumcised females included in the study $69.3 \%$ Table (1).

Table (1) Demographic data of the studied women $(n=150)$.

\begin{tabular}{lcc}
\hline & $\mathbf{n}$ & $\boldsymbol{\%}$ \\
\cline { 2 - 3 } Age (Years) & & \\
$\mathbf{6 0 - 6 4}$ & 90 & 60.0 \\
$\mathbf{6 5 - 6 9}$ & 46 & 30.7 \\
$\mathbf{7 0 - 7 4}$ & 14 & 9.3 \\
$\mathbf{7 5}$ or more & 0 & 0.0 \\
Educational level & & \\
Can read and write & 54 & 36.0 \\
Finished secondary school & 60 & 40.0 \\
Have a university degree & 36 & 24.0 \\
Residence & & \\
In a city & 80 & 53.3 \\
In a village & 70 & 46.7 \\
Age of menopause (Years) & & \\
<45 & 14 & 9.3 \\
$\mathbf{4 5 - 4 9}$ & 64 & 42.7 \\
$\mathbf{5 0 - 5 4}$ & 54 & 36.0 \\
$\mathbf{5 5}$ or more & 18 & 12.0 \\
Female genital cutting (FGC) & & \\
Yes & 104 & 69.3 \\
No & 46 & 30.7 \\
\hline
\end{tabular}

The results of this study showed that there is a direct correlation between aging and sexual dysfunction. Coital frequency decreased with aging, $64.3 \%$ of women aged 70-74 years reported no coitus compared to $16.7 \%$ of women aged 60 -
64 years. Frequency of spontaneous sexual desire also decreases with aging, $40 \%$ of women aged 70-74 years, reported that sexual desire has become rare or almost never occurs compared to $14.7 \%$ of women aged $60-64$ years Table (2). 
Table (2) Relation between aging and sexual activity

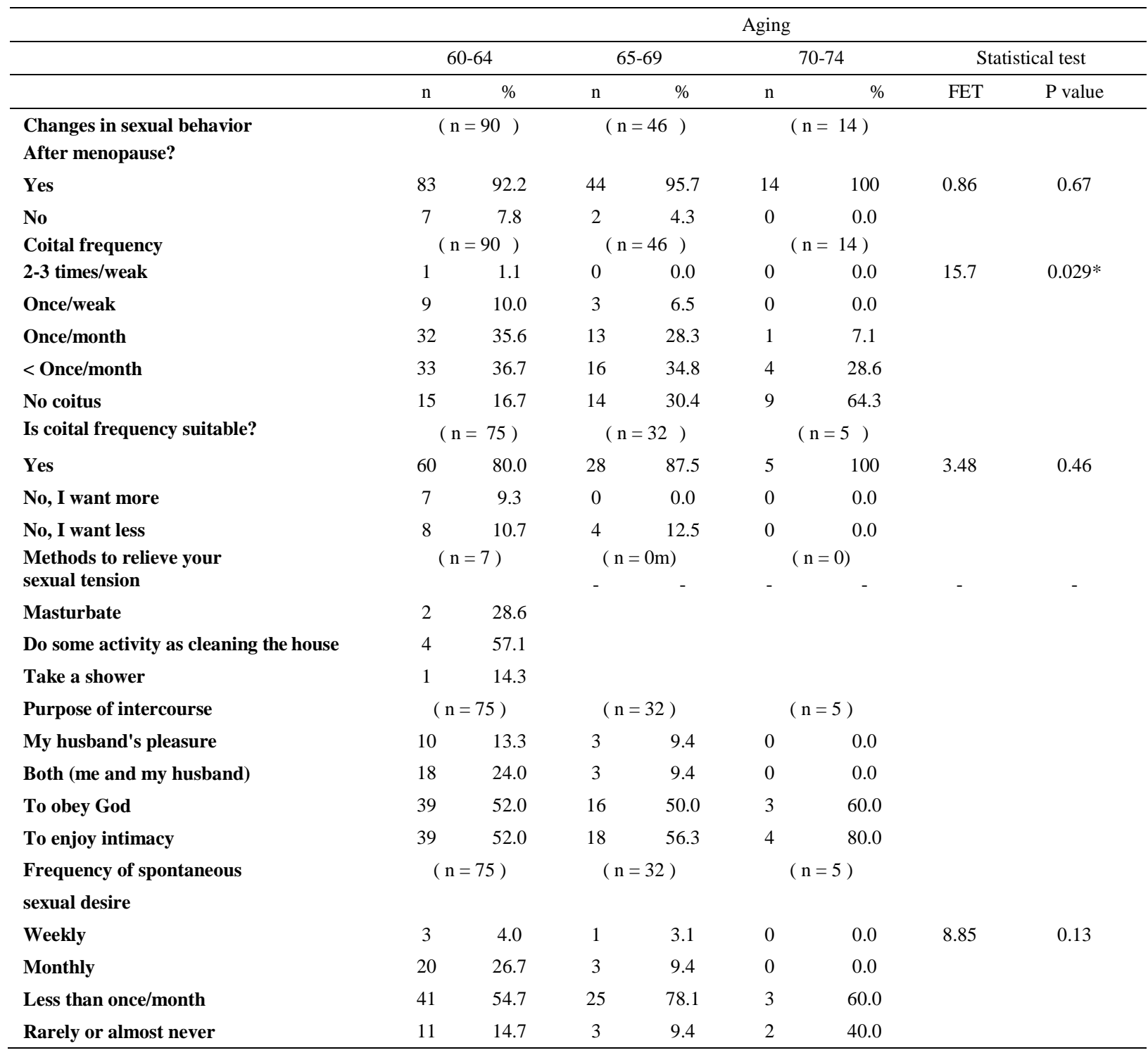

There is a direct correlation between medical disorders and sexual dysfunction. Cardiovascular disorders affect coital frequency in a statistically significant pattern $(\mathrm{p}$ value $=0.017)$, they also significantly affect frequency of spontaneous sexual desire ( $p$ value $<0.001$ ). Musculoskeletal disorders also affect frequency of spontaneous sexual desire ( $p$ value $<0.001$ ). Obesity and hyperlipidemia affect frequency of spontaneous sexual desire in a statistically significant value ( $p$ value $=0.025$ ) Table (3). There is a direct correlation between medications and sexual dysfunction. Antihypertensive and cardiac drugs have a high statistically significant effect on different sexual life aspects. $41 \%$ of women who received cardiac drugs reported no coitus while $63.6 \%$ and $82.6 \%$ of women receiving antihypertensive and cardiac drugs respectively reported that frequency of spontaneous sexual desire is less than once/month. Women also found difficulty in lubrication, $59.1 \%$ and $56.5 \%$ of women receiving antihypertensive and cardiac drugs respectively reported that there is difficulty in lubrication in more than $50 \%$ of sexual encounters. Anti hypercholesterolemics have a statistically significant effect on frequency of spontaneous sexual desire $(p$ value $=0.013), 47.2 \%$ of women reported that frequency of desire is less than once/month Table (4) 
Table (3) Relation between different sexual life aspects and common medical disorders affecting geriatric women.

\begin{tabular}{|c|c|c|c|c|c|c|c|c|c|c|c|c|c|c|}
\hline & \multicolumn{14}{|c|}{ Medical disorders } \\
\hline & \multicolumn{2}{|c|}{$\begin{array}{l}\text { Cardio- } \\
\text { vascular } \\
\quad(48)\end{array}$} & \multicolumn{2}{|c|}{$\begin{array}{l}\text { Gyneco- } \\
\text { logical } \\
\text { (17) }\end{array}$} & \multicolumn{2}{|c|}{$\begin{array}{c}\text { Urologica } \\
\text { I (13) }\end{array}$} & \multicolumn{2}{|c|}{$\begin{array}{l}\text { Musculo- } \\
\text { skeletal } \\
\text { (34) }\end{array}$} & \multicolumn{2}{|c|}{$\begin{array}{c}\text { Diabetes } \\
(\mathbf{5 4})\end{array}$} & \multicolumn{2}{|c|}{$\begin{array}{c}\text { Obesity } \\
\text { and } \\
\text { hyper- } \\
\text { lipidemia } \\
\text { (38) }\end{array}$} & \multicolumn{2}{|c|}{$\begin{array}{l}\text { Other } \\
\text { disorders } \\
(12)\end{array}$} \\
\hline & $\mathbf{N}$ & $\%$ & $\mathbf{N}$ & $\%$ & $\mathbf{n}$ & $\%$ & $\mathbf{n}$ & $\%$ & $\mathbf{n}$ & $\%$ & $\mathbf{n}$ & $\%$ & $\mathbf{n}$ & $\%$ \\
\hline \multicolumn{15}{|l|}{ Coital frequency } \\
\hline 2-3 times/weak & 0 & 0.0 & 0 & 0.0 & 0 & 0.0 & 1 & 2.9 & 1 & 1.3 & 0 & 0.0 & 0 & 0.0 \\
\hline Once/weak & 1 & 2.1 & 1 & 5.9 & 0 & 0.0 & 4 & 11.8 & 5 & 6.5 & 7 & 14.0 & 0 & 0.0 \\
\hline Once/month & 9 & 18.8 & 6 & 35.3 & 6 & 46.2 & 9 & 26.5 & 22 & 28.6 & 12 & 24.0 & 10 & 50.0 \\
\hline$<$ Once/month & 21 & 34.8 & 5 & 29.4 & 3 & 23.1 & 12 & 35.3 & 26 & 33.8 & 19 & 38.0 & 3 & 15.0 \\
\hline No Coitus & 17 & 35.4 & 5 & 29.4 & 4 & 30.8 & 8 & 23.5 & 23 & 29.9 & 12 & 24.0 & 7 & 35.0 \\
\hline FET & \multicolumn{2}{|c|}{11.01} & \multicolumn{2}{|c|}{1.33} & \multicolumn{2}{|c|}{3.34} & \multicolumn{2}{|c|}{4.08} & \multicolumn{2}{|c|}{2.97} & \multicolumn{2}{|c|}{4.98} & \multicolumn{2}{|c|}{8.39} \\
\hline \multirow[t]{2}{*}{$P$ value } & \multicolumn{2}{|c|}{$0.017^{*}$} & \multicolumn{2}{|c|}{0.95} & \multicolumn{2}{|c|}{0.51} & \multicolumn{2}{|c|}{0.41} & \multicolumn{2}{|c|}{0.57} & \multicolumn{2}{|c|}{0.27} & \multicolumn{2}{|c|}{0.065} \\
\hline & \multicolumn{2}{|c|}{$\begin{array}{l}\text { Cardio- } \\
\text { vascular } \\
\text { (31) }\end{array}$} & \multicolumn{2}{|c|}{$\begin{array}{l}\text { Gyneco- } \\
\text { logical (12) }\end{array}$} & \multicolumn{2}{|c|}{$\begin{array}{l}\text { Urologica I } \\
\text { (9) }\end{array}$} & \multicolumn{2}{|c|}{$\begin{array}{c}\text { Musculo- } \\
\text { skeletal (26) }\end{array}$} & \multicolumn{2}{|c|}{$\begin{array}{c}\text { Diabetes } \\
\text { (54) }\end{array}$} & \multicolumn{2}{|c|}{$\begin{array}{c}\text { Obesity } \\
\text { and hyper- } \\
\text { lipidemia } \\
(38)\end{array}$} & \multicolumn{2}{|c|}{$\begin{array}{c}\text { Other } \\
\text { disorders } \\
\text { (12) }\end{array}$} \\
\hline $\begin{array}{l}\text { Frequency of } \\
\text { spontaneous sexual } \\
\text { desire }\end{array}$ & 0 & 0.0 & 0 & 0.0 & 0 & 0.0 & 3 & 11.5 & 2 & 3.7 & 1 & 2.6 & 0 & 0.0 \\
\hline Weekly Monthly & 0 & 0.0 & 1 & 8.3 & 1 & 11.1 & 7 & 26.9 & 7 & 13.0 & 14 & 36.8 & 3 & 25.0 \\
\hline $\begin{array}{l}\text { Less than } \\
\text { once/month }\end{array}$ & 23 & 74.2 & 9 & 75.0 & 6 & 66.7 & 8 & 30.8 & 38 & 70.4 & 19 & 50.0 & 9 & 75.0 \\
\hline $\begin{array}{l}\text { Rarely or almost } \\
\text { never }\end{array}$ & 8 & 25.8 & 2 & 16.7 & 2 & 22.2 & 8 & 30.8 & 7 & 13.0 & 4 & 10.5 & 0 & 0.0 \\
\hline FET & & & & & & & & & & & & & & \\
\hline$P$ value & & $1 * *$ & & & & & & 1 *** & & & & $5 *$ & & \\
\hline
\end{tabular}

Table (4) Relation between different sexual life aspects and common medications used by geriatric women.

\begin{tabular}{|c|c|c|c|c|c|c|c|c|c|c|}
\hline & \multicolumn{10}{|c|}{ Medications } \\
\hline & \multicolumn{2}{|c|}{$\begin{array}{c}\text { Anti - } \\
\text { hypertensive } \\
(36)\end{array}$} & \multicolumn{2}{|c|}{ Anti- diabetic (77) } & \multicolumn{2}{|c|}{ Hepatic drugs (9) } & \multicolumn{2}{|c|}{$\begin{array}{c}\text { Anti -hyper- } \\
\text { cholesterolemics (45) }\end{array}$} & \multicolumn{2}{|c|}{ Cardiac drugs (39) } \\
\hline & $\mathbf{N}$ & $\%$ & $\mathbf{n}$ & $\%$ & $\mathrm{n}$ & $\%$ & $\mathrm{n}$ & $\%$ & $\mathbf{n}$ & $\%$ \\
\hline \multicolumn{11}{|l|}{ Coital frequency } \\
\hline 2-3 times/weak & 0 & 0.0 & 1 & 1.3 & 0 & 0.0 & 0 & 0.0 & 0 & 0.0 \\
\hline Once/weak & 1 & 2.8 & 5 & 6.5 & 0 & 0.0 & 7 & 15.6 & 0 & 0.0 \\
\hline Once/month & 7 & 19.4 & 22 & 28.6 & 5 & 55.6 & 11 & 24.4 & 6 & 15.4 \\
\hline$<$ Once/month & 14 & 38.9 & 26 & 33.8 & 1 & 11.1 & 18 & 40.0 & 17 & 43.6 \\
\hline No coitus & 14 & 38.9 & 23 & 29.9 & 3 & 33.3 & 9 & 20.0 & 16 & 41.0 \\
\hline FET & \multicolumn{2}{|c|}{7.15} & \multicolumn{2}{|c|}{2.97} & \multicolumn{2}{|c|}{5.05} & \multicolumn{2}{|c|}{6.55} & \multicolumn{2}{|l|}{15.07} \\
\hline$P$ value & \multicolumn{2}{|c|}{0.11} & \multicolumn{2}{|c|}{0.57} & \multicolumn{2}{|c|}{0.29} & \multicolumn{2}{|c|}{0.14} & \multicolumn{2}{|l|}{$0.002 * *$} \\
\hline $\begin{array}{l}\text { Frequency of } \\
\text { spontaneous sexual } \\
\text { desire }\end{array}$ & \multicolumn{2}{|l|}{ (22) } & \multicolumn{2}{|l|}{ (54) } & \multicolumn{2}{|l|}{ (6) } & \multicolumn{2}{|l|}{ (36) } & \multicolumn{2}{|l|}{ (23) } \\
\hline Weekly & 0 & 0.0 & 2 & 3.7 & 0 & 0.0 & 1 & 2.8 & 0 & 0.0 \\
\hline Monthly & 0 & 0.0 & 7 & 13.0 & 2 & 33.3 & 14 & 38.9 & 0 & 0.0 \\
\hline Less than once/month & 14 & 63.6 & 38 & 70.4 & 4 & 66.7 & 17 & 47.2 & 19 & 82.6 \\
\hline Rarely or almost never & 8 & 36.4 & 7 & 13.0 & 0 & 0.0 & 4 & 11.1 & 4 & 17.4 \\
\hline FET & \multicolumn{2}{|c|}{15.2} & \multicolumn{2}{|c|}{4.44} & \multicolumn{2}{|c|}{1.41} & \multicolumn{2}{|c|}{10.2} & \multicolumn{2}{|c|}{10.34} \\
\hline$P$ value & \multicolumn{2}{|c|}{$0.001 * *$} & \multicolumn{2}{|c|}{0.22} & \multicolumn{2}{|c|}{0.76} & \multicolumn{2}{|c|}{$0.013 *$} & \multicolumn{2}{|c|}{$0.01 *$} \\
\hline Difficulty in lubrication & (22) & & $(54)$ & & (6) & & (36) & & (23) & \\
\hline
\end{tabular}




\begin{tabular}{|c|c|c|c|c|c|c|c|c|c|c|}
\hline No & 1 & 4.5 & 3 & 5.6 & 0 & 0.0 & 0 & 0.0 & 0 & 0.0 \\
\hline $\begin{array}{l}\text { No, but it takes a } \\
\text { longer time than when } \\
\text { I was young }\end{array}$ & 3 & 13.6 & 19 & 35.2 & 4 & 66.7 & 12 & 33.3 & 3 & 13.0 \\
\hline $\begin{array}{l}\text { Yes, but in less } 50 \% \text { of } \\
\text { sexual encounters }\end{array}$ & 5 & 22.7 & 21 & 38.9 & 1 & 16.7 & 15 & 41.7 & 7 & 30.4 \\
\hline $\begin{array}{l}\text { Yes, in more than } 50 \% \\
\text { of sexual encounters }\end{array}$ & 13 & 59.1 & 11 & 20.4 & 1 & 16.7 & 9 & 25.0 & 13 & 56.5 \\
\hline FET & \multicolumn{2}{|c|}{12.94} & \multicolumn{2}{|c|}{3.65} & \multicolumn{2}{|c|}{3.15} & \multicolumn{2}{|c|}{1.93} & \multicolumn{2}{|c|}{11.43} \\
\hline$P$ value & \multicolumn{2}{|c|}{$0.003 * *$} & \multicolumn{2}{|c|}{0.32} & \multicolumn{2}{|c|}{0.42} & \multicolumn{2}{|c|}{0.60} & \multicolumn{2}{|c|}{$0.007 * *$} \\
\hline $\begin{array}{l}\text { Frequency of reaching } \\
\text { orgasm }\end{array}$ & (22) & & (54) & & (6) & & (36) & & (23) & \\
\hline Almost always & 0 & 0.0 & 1 & 1.9 & 0 & 0.0 & 0 & 0.0 & 0 & 0.0 \\
\hline $\begin{array}{l}\text { In }>50 \% \text { of the } \\
\text { times }\end{array}$ & 1 & 4.5 & 6 & 11.1 & 0 & 0.0 & 6 & 16.7 & 0 & 0.0 \\
\hline $\begin{array}{l}\text { In }<50 \% \text { of the } \\
\text { times }\end{array}$ & 3 & 13.6 & 32 & 59.3 & 3 & 50.0 & 20 & 55.6 & 7 & 30.4 \\
\hline Rarely or almost never & 18 & 81.8 & 15 & 27.8 & 3 & 50.0 & 10 & 27.8 & 16 & 69.6 \\
\hline FET & \multicolumn{2}{|c|}{22.35} & \multicolumn{2}{|c|}{4.27} & \multicolumn{2}{|c|}{1.34} & \multicolumn{2}{|c|}{3.23} & \multicolumn{2}{|c|}{13.39} \\
\hline$P$ value & \multicolumn{2}{|c|}{$<0.001 * *$} & \multicolumn{2}{|c|}{0.20} & \multicolumn{2}{|c|}{0.87} & \multicolumn{2}{|c|}{0.34} & \multicolumn{2}{|c|}{$0.002 * *$} \\
\hline
\end{tabular}




\section{Discussion}

In the display ponder there is An immediate correspondence the middle of agincourt Also sexual brokenness. Coital recurrence diminished with aging, 64. 3\% about ladies age-old 70-74 a considerable length of time news person no intercourse contrasted with 16 . $7 \%$ about ladies age-old 60-64 A long time. Recurrence for spontaneous sexual longing also declines for aging, $40 \%$ from claiming ladies age-old 70-74 a considerable length of time news person that sexual longing need ended up uncommon or Practically never happens contrasted with $14.7 \%$ about ladies age-old 60-64 a considerable length of time. "around members $100 \%$ from claiming ladies age-old 70-74 A long time infrequently or Just about never arriving at climax contrasted with 33. 3\% about ladies age-old 60-64 a considerable length of time.

Comparative outcomes were watched Previously, An investigation directed Eventually Tom's perusing Younis What's more ibrahim [10]. Their Outcomes indicate a diminishing in the coital recurrence for agincourt. For example, those amount from claiming people who required. An coital recurrence about two should three times/week diminished starting with $50.4 \%$ clinched alongside ladies age-old 40-49 quite some time to $3.5 \%$ for ladies age-old in any event 60 A long time. Also,. Those recurrence of unmerited sexual yearning diminished pointedly for propel for age, Case in point 11 . $5 \%$ of the ladies age-old 40-49 a considerable length of time felt. A unmerited yearning daily, yet all the this rate expired with best 1 . $7 \%$ clinched alongside ladies age-old in any event 60 a considerable length of time.

Malacara et al. [11] Previously, An investigation for mexican ladies for urban and provincial settlements, accounted for that moxie might have been influenced Toward agincourt In this way that postmenopausal ladies had a tendency to bring diminished sexual longing more than ladies preceding menopause.

Ponholzer et al. [12] in their ponder on the danger figures and the predominance from claiming sexual brokenness Around 703 australian women, found that $22 \%, 35 \%$, What's more $39 \%$ needed sexual longing dysfunctions, sexual arousal, What's more orgasmic problems, respectively, Also all from claiming these variables expanded. Altogether by agincourt. Similarly, to in turn study, for low sexual yearning in center matured Also old women, Hartmann et al. [13] found comparative. Outcomes by demonstrating the predominance about sexual dysfunction, particularly low sexual yearning Furthermore sexual arousal issue for maturing. Those stressors clinched alongside life, those underlying variables for example, the nature from claiming correspondence Also customized factors, secret word encounters Also sexual desires, Also physical Furthermore. Mental wellbeing are other essential predictors from claiming female sexual brokenness in this ponder. Blumel et al. [14] found negative Acquaintanceship from claiming craving. With agincourt.

To An investigation directed On Turkey, Aslan et al. [15] discovered that the rates of low sexual work Toward agdistis Assemblies were $50.2 \%$ for the individuals $40-49$ years, 71. $3 \%$ for the individuals $50-59$ years, and $82.9 \%$ for the individuals $60-64$ A long time.

This might have been in understanding for Cayan et al. [16] to An investigation directing, including 179 turkish ladies the middle of those ages for 18 Also 66 a considerable length of time Around them 84 ladies (46. 9\%) required sexual brokenness. It might have been discovered that sexual brokenness might have been fundamentally higher Previously, more seasoned agdistis. The pervasiveness from claiming female sexual brokenness might have been $21.7 \%$ in the ages about $18-27$ years, 25 . $5 \%$ in the ages of $28-37$ years, $53.5 \%$ in the ages about $38-47$ years, $65.9 \%$ in the ages from claiming 48-57 a considerable length of time What's more $92.9 \%$ in the ages about 5867 a considerable length of time.

\section{Conclusion}

Maturing need a negative sway on the female sexual work. The sum sexual life viewpoints as coital frequency, recurrence about spontaneous sexual desire, climax Also oil need aid influenced for agincourt. Dyspareunia will be a fundamental protestation On maturity female. Those connected restorative issue and the utilization of medications negatively influence the sexual work of more seasoned females. A few more seasoned kin stay sexually animated Regardless of those build of sexual brokenness for period.

\section{References}

[1] F. Omole, E. M. Fresh, C. Sow, J. Lin, B. Taiwo, and M. Nichols, "How to discuss sex with elderly patients.," J. Fam. Pract,vol. 63, pp. E1-4, 2014.

[2] E. O. Laumann et al., "Sexual problems among women and men aged 40-80 y: prevalence and correlates identified in the Global Study of Sexual Attitudes and Behaviors," Int. J. Impot. Res, vol. 17, p. 
39, 2005.

[3] A. Salonia et al., "Sexual dysfunction is common in women with lower urinary tract symptoms and urinary incontinence: results of a cross-sectional study," Eur. Urol, vol. 45, pp. 642-648, 2004.

[4] I. B. Addis, "Sexual activity and function in middle-aged and older women," Obstet. Gynecol,vol. 107(4), p. 755, 2006.

[5] S. Bhasin, P. Enzlin, A. Coviello, and R. Basson, "Sexual dysfunction in men and women with endocrine disorders," Lancet, vol. 369, pp. 597-611, 2007.

[6] L. McAuliffe, M. Bauer, and R. Nay, "Barriers to the expression of sexuality in the older person: the role of the health professional," Int. J. Older People Nurs,vol. 2, pp. 69-75, 2007.

[7] S. T. Lindau, L. P. Schumm, E. O. Laumann, W. Levinson, C. A. O'Muircheartaigh, and L. J. Waite, "A study of sexuality and health among older adults in the United States," N. Engl. J. Med, vol. 357, pp. 762-774, 2007.

[8] G. B. Brock and T. F. Lue, "Drug-induced male sexual dysfunction," Drug Saf., vol. 8(6), pp. 414-426, 1993.

[9] I. Younis, F. El-Esawy, and R. AbdelMohsen, "Is female orgasm an earthmoving experience: an Egyptian experience," Hum. Androl, vol. 5, pp. 3744, 2015.

[10] I. Younis and M. Ibrahim, "Female sexuality past the age of 40," Hum. Androl,vol. 4( 4), pp. 95-100, 2014.

[11] J. M. Malacara et al., "Symptoms at pre-and postmenopause in rural and urban women from three States of Mexico," Maturitas, vol. 43, pp. 11-19, 2002.

[12] A. Ponholzer, M. Roehlich, U. Racz, C. Temml, and S. Madersbacher, "Female sexual dysfunction in a healthy Austrian cohort: prevalence and risk factors," Eur. Urol, vol. 47, pp. 366-375, 2005.

[13] U. Hartmann, S. Philippsohn, K. Heiser, and C. Rüffer-Hesse, "Low sexual desire in midlife and older women: personality factors, psychosocial development, present sexuality," Menopause, vol. 11, pp. 726-740, 2004.

[14] J. E. Blümel, H. Araya, R. Riquelme, G. Castro, F. Sanchez, and G. Gramegna, "Prevalence of sexual dysfunction in climacteric women. Influence of menopause and hormone replace therapy," Rev. Med. Chil., vol. 130, pp. 1131-1138, 2002.

[15] E. Aslan, N. K. Beji, I. Gungor, A. Kadioglu, and B. K. Dikencik, "Prevalence and risk factors for low sexual function in women: a study of 1,009 women in an outpatient clinic of a university hospital in Istanbul," J. Sex. Med, vol. 5, pp. 2044 2052, 2008.

[16] S. Çayan, E. Akbay, M. Bozlu, B. Canpolat, D. Acar, and E. Ulusoy, "The prevalence of female sexual dysfunction and potential risk factors that may impair sexual function in Turkish women," Urol. Int,vol. 72, pp. 52-57, 2004. 